\title{
Runs of homozygosity reveal signatures of positive selection for reproduction traits in breed and non-breed horses
}

\author{
Julia Metzger ${ }^{1}$, Matthias Karwath², Raul Tonda ${ }^{3}$, Sergi Beltran³ ${ }^{3}$ Lídia Águeda ${ }^{3}$, Marta Gut ${ }^{3}$, Ivo Glynne Gut ${ }^{3}$
} and Ottmar Distl ${ }^{1^{*}}$

\begin{abstract}
Background: Modern horses represent heterogeneous populations specifically selected for appearance and performance. Genomic regions under high selective pressure show characteristic runs of homozygosity (ROH) which represent a low genetic diversity. This study aims at detecting the number and functional distribution of ROHs in different horse populations using next generation sequencing data.

Methods: Next generation sequencing was performed for two Sorraia, one Dülmen Horse, one Arabian, one Saxon-Thuringian Heavy Warmblood, one Thoroughbred and four Hanoverian. After quality control reads were mapped to the reference genome EquCab2.70. ROH detection was performed using PLINK, version 1.07 for a trimmed dataset with $11,325,777$ SNPs and a mean read depth of 12. Stretches with homozygous genotypes of $>40 \mathrm{~kb}$ as well as $>400 \mathrm{~kb}$ were defined as ROHs. SNPs within consensus ROHs were tested for neutrality. Functional classification was done for genes annotated within ROHs using PANTHER gene list analysis and functional variants were tested for their distribution among breed or non-breed groups.

Results: $\mathrm{ROH}$ detection was performed using whole genome sequences of ten horses of six populations representing various breed types and non-breed horses. In total, an average number of $3492 \mathrm{ROH}$ s were detected in windows of a minimum of 50 consecutive homozygous SNPs and an average number of 292 $\mathrm{ROHs}$ in windows of 500 consecutive homozygous SNPs. Functional analyses of private ROHs in each horse revealed a high frequency of genes affecting cellular, metabolic, developmental, immune system and reproduction processes. In non-breed horses, 198 ROHs in 50-SNP windows and seven ROHs in 500-SNP windows showed an enrichment of genes involved in reproduction, embryonic development, energy metabolism, muscle and cardiac development whereas all seven breed horses revealed only three common ROHs in 50-SNP windows harboring the fertility-related gene YES1. In the Hanoverian, a total of 18 private ROHs could be shown to be located in the region of genes potentially involved in neurologic control, signaling, glycogen balance and reproduction. Comparative analysis of homozygous stretches common in all ten horses displayed three ROHs which were all located in the region of KITLG, the ligand of KIT known to be involved in melanogenesis, haematopoiesis and gametogenesis.
\end{abstract}

Conclusions: The results of this study give a comprehensive insight into the frequency and number of ROHs in various horses and their potential influence on population diversity and selection pressures. Comparisons of breed and non-breed horses suggest a significant artificial as well as natural selection pressure on reproduction performance in all types of horse populations.

Keywords: Runs of homozygosity, Horse population, Selection signature, Reproduction, KITLG

\footnotetext{
* Correspondence: ottmar.distl@tiho-hannover.de

'Institute for Animal Breeding and Genetics, University of Veterinary Medicine

Hannover, Bünteweg 17p, 30559 Hannover, Germany

Full list of author information is available at the end of the article
}

(C) 2015 Metzger et al. Open Access This article is distributed under the terms of the Creative Commons Attribution 4.0 International License (http://creativecommons.org/licenses/by/4.0/), which permits unrestricted use, distribution, and reproduction in any medium, provided you give appropriate credit to the original author(s) and the source, provide a link to the Creative Commons license, and indicate if changes were made. The Creative Commons Public Domain Dedication waiver (http://creativecommons.org/publicdomain/zero/1.0/) applies to the data made available in this article, unless otherwise stated. 


\section{Background}

The modern horse population represents a particularly heterogenous group influenced over the time by various selective pressures [1]. However, in studies on genetic diversity a contrasting homogeneity within breeds or non-breeds has been observed [2-4]. In particular breeds like the Arabian, Hanoverian and Saxon-Thuringian Heavy Warmblood have been shaped by intense human selection for specific abilities and characteristics that meet with requirements for optimal performance whereas environmental conditions have particularly influenced non-breed horses. The Dülmen Horse and the Sorraia can be characterized as non-breeds with a robust constitution for primitive living conditions not subjected to human selection criteria for specific breeding aims but to natural selection [5-7]. Strong selective pressures result in a reduction of genetic diversity which is characterized by long stretches of consecutive homozygous genotypes in the genome known as runs of homozygosity ( $\mathrm{ROH}$ ) [8-11]. Size and frequency of ROHs give evidence for relatedness within and in-between populations.

In horses, signals of selection have been investigated in 744 horses of 33 breeds using whole-genome single nucleotide polymorphism (SNP) array data [1]. Potential genomic targets of selection were observed within breeds by $\mathrm{F}_{\mathrm{ST}^{-}}$-based statistics in 500-kb windows and revealed common haplotypes in the region of coat color genes, size and performance traits. The highest signature of selection was found in the Paint and Quarter Horse on ECA18 in the region of the myostatin gene (MSTN). Positively selected loci for performance have also been detected in a Thoroughbred population study based on microsatellite markers [12]. Candidate regions for exercise adaption including fatty acid oxidation, increased insulin sensitivity and muscle strength have been suggested as potential selection targets.

Signals of selection have also been investigated in other mammals including cattle, dog, pig and human, frequently scanning ROHs as diversity indices [1, 9-11, 13]. In human, ROHs were considered valuable for population demographic analyses and allowed reliable differentiation of human indigenous populations from distinct continents [14]. Shorter homozygous stretches helped to characterize population specific properties whereas $\mathrm{ROH}$ longer than $0.5 \mathrm{Mb}$ could be shown to be frequent in all populations $[15,16]$. It was proposed that ROHs longer than $1 \mathrm{Mb}$ were quite more common in outbred individuals. In addition to population genetic applications, $\mathrm{ROH}$ detection was suggested to be valuable for mapping of causative mutations for recessive diseases [17, 18]. A study for schizophrenia identified nine risk $\mathrm{ROHs}$ which were significantly more frequent in affected patients and harbored disease-associated genes [19].
In domestic animals, especially performance related phenotypes and breed specific characteristics were mainly in focus of $\mathrm{ROH}$ analyses $[9,20]$. A whole-genome comparative detection of $\mathrm{ROHs}$ in a sliding window approach was applied for pigs in wild and domesticated populations [9]. Two overlapping $\mathrm{ROHs}$ were identified in the European breeds harboring genes involved in cell differentiation. In Large White and Landrace pigs an exclusive $\mathrm{ROH}$ could be shown to be located in the region of the growth related pleiomorphic adenoma gene 1 (PLAG1). Further breed specific $\mathrm{ROH}$ analyses for Chinese and Western pigs revealed loci under selection important for highaltitude adaption in Tibetan pigs as well as a coat color locus in the region of endothelin receptor type $B$ (EDNRB) in Chinese belted pigs [21].

Signatures of selection affecting coat color and body size traits could also be observed in genome-wide $\mathrm{ROH}$ scans for dogs [22]. It was suggested that ancestral genetic variations were transformed into specific characteristics of different dog breeds $[13,22]$. Next generation sequencing (NGS) data from dogs and wolves revealed regions of potential selection in domesticated dogs which affect metabolism and thus suggest a potential adaption to starch digestion $[13,23]$. In the Lundehund, fifteen regions with long-range haplotypes indicated potential signatures of positive selection for polydactyly, body size and male fertility [24]. In cattle, a large number of $\mathrm{ROHs}$ have been shown to be widely distributed among various breeds and demonstrated its utility for prediction of inbreeding coefficients and relatedness $[10,25,26]$. Haplotype-frequency based approaches revealed signatures of selection in the region of genes affecting reproduction and muscle formation [27]. A genome-wide scan in Holstein cattle identified milk yield, composition, reproduction and behavioral traits in potentially selected regions [28]. Similar observations were made in an U.S. Holstein cattle study which investigated the distribution of $\mathrm{ROHs}$ in different milk production groups [29]. Forty genomic regions in potential signatures of selection were identified in SNP array data harboring loci for milk, fat and protein yield. However, the use of SNP arrays for $\mathrm{ROH}$ detection was suggested to be limited mainly for low SNP density reasons [27, 28, 30]. Higher resolution genomic analyses on basis of wholegenome data enabled the use of 15 million SNPs from 43 Fleckvieh cattle for powerful detection of selected traits [20]. Candidate regions for coat color, neurobehavioral functioning and sensory perception were found in $\mathrm{ROH}$ regions suggesting domestication-related signatures of selection. The accuracy of $\mathrm{ROH}$ detection in NGS data was shown to be high if corrected for bias by hidden errors in genotyping data [31].

In this study, whole-genome sequences of ten horses were used for analysis of $\mathrm{ROHs}$ in a sliding window approach. 50-SNP and 500-SNP windows were chosen 
for reliable detection of $\mathrm{ROHs}$ of different sizes. $\mathrm{ROHs}$ exclusively found in individual horses or breeds were further investigated for their gene content potentially affected by targeted selection for specific appearance and function.

\section{Results}

\section{Sequencing and variant detection}

Whole-genome sequences of a Dülmen Horse, two Sorraia, an Arabian, a Saxon-Thuringian Heavy Warmblood descendent from the Old-Oldenburg breed, a Thoroughbred and four Hanoverian were obtained using NGS. Mapping to the reference genome EquCab2.70 resulted in a mean coverage of $19.90 \mathrm{X}$ for the Dülmen Horse, 17.34X and 17.55X for the two Sorraia, 19.14X for the Arabian, 20.06X for the SaxonThuringian Heavy Warmblood, 5.92X for the Thoroughbred and 15.66X-35.18X for the four Hanoverian (Additional file 1). Raw data of variant detection revealed 3,865,613-7,147,081 SNPs and 698,724-992,338 insertions/deletions (INDELs) in each of the ten horses. After stringent quality control, a total of 11,325,777 SNPs were filtered out and used for $\mathrm{ROH}$ analysis. The mean heterozygosity for these SNPs per site was 0.28 in the Dülmen Horse and Arabian, 0.24 and 0.25 in the Sorraia horse, 0.29 in the Saxon-Thuringian Heavy Warmblood, 0.29 in the four Hanoverian and 0.21 in the Thoroughbred.

\section{Sequence error estimation}

We estimated sequence errors on the basis of SNP50 BeadChip data in five horses. The results of BeadChip analysis were assumed to be error free. The rate of falsenegative SNPs was calculated based on heterozygous SNPs in BeadChip data which were homozygous in NGS data. We detected false-negative rates of $0.24-0.26$ in the four Hanoverian and 0.22 in the Arabian (Table 1). The false-positive rate was at $3.8 \times 10^{-4}$ to $9.8 \times 10$ ${ }^{-4}$ using all SNP positions of the BeadChip data. More stringent error estimations in long SNPChip $\mathrm{ROH}$ regions of $>10 \mathrm{Mb}$ compared to filtered NGS sequence revealed even lower error rates at $3.1 \times 10^{-4}$ to $5.9 \times 10^{-5}$.

\section{ROH detection}

An average number of $3492 \mathrm{ROHs}$ was detected for the ten horses in windows of minimum amount of 50 homozygous SNPs and an average number of $292 \mathrm{ROHs}$ in windows of 500 homozygous SNPs (Table 2). The number of smaller ROHs of $40-59 \mathrm{~kb}$ was almost equally distributed in all ten horses, whereas $\mathrm{ROHs}>59 \mathrm{~kb}$ were comparatively high in the two Sorraia horses and in the thoroughbred (Fig. 1). $\mathrm{ROH}$ detection in larger windows of $>400 \mathrm{~kb}$ revealed even a more distinct distribution, showing ROHs particularly frequent in the Sorraia and Thoroughbred but also in the Arabian. As indicated by the number and size of $\mathrm{ROH}$, the total length of $\mathrm{ROHs}$ in sliding windows of at least 50 SNPs was notably high in the Thoroughbred $(953 \mathrm{Mb})$ and the two Sorraia (867 and $730 \mathrm{Mb}$ ) and comparatively high in the Arabian (566 Mb, Additional file 2). The $\mathrm{F}_{\mathrm{ROH}}$ estimated for 50 SNP windows were 0.43 in the Thoroughbred, 0.39 and 0.33 in the Sorraia horses, 0.25 in the Arabian. The four Hanoverian as well as the Saxon-Thuringian Heavy Warmblood and the Dülmen Horse showed $\mathrm{F}_{\mathrm{ROH}^{-}}$ ranging from 0.18 to 0.22 . Similar distributions of $F_{\mathrm{ROH}}$ could be observed for 500-SNP windows, showing the highest values of 0.18 in the Thoroughbred as well as 0.16 and 0.12 in the Sorraia horses.

Table 1 Sequence error estimation

\begin{tabular}{|c|c|c|c|c|c|}
\hline \multirow[t]{2}{*}{ Number of SNPs } & Horse 4 & Horse 5 & Horse 6 & Horse 7 & Horse 9 \\
\hline & Hanoverian & Hanoverian & Hanoverian & Hanoverian & Arabian \\
\hline Heterozygous in NGS data & 891,514 & 815,810 & 833,149 & 832,549 & 812,952 \\
\hline Heterozygous in BeadChip data & 16,426 & 15,469 & 15,873 & 15,987 & 14,008 \\
\hline Homozygous in BeadChip data & 33,403 & 34,360 & 33,956 & 33,842 & 35,821 \\
\hline Heterozygous in NGS and BeadChip data & $3,555(7.14 \%)$ & $3,239(6.50 \%)$ & $3,306(6.64 \%)$ & $3,396(6.82 \%)$ & $2,960(5.94 \%)$ \\
\hline $\begin{array}{l}\text { Heterozygous in BeadChip and homozygous in } \\
\text { NGS data }\end{array}$ & $12,867(25.83 \%)$ & $12,223(24.54 \%)$ & 12,565 (25.22 \%) & 12,589 (25.27\%) & $11,047(22.17 \%)$ \\
\hline \multicolumn{6}{|l|}{ (False-negative rate) } \\
\hline $\begin{array}{l}\text { Homozygous in BeadChip and heterozygous in } \\
\text { NGS data }\end{array}$ & $\begin{array}{l}19\left(3.8 \times 10^{-4}\right. \\
\text { of all } 49,813\end{array}$ & $\begin{array}{l}29\left(5.8 \times 10^{-4}\right. \\
\text { of all } 49,813\end{array}$ & $\begin{array}{l}38\left(7.6 \times 10^{-4}\right. \\
\text { of all } 49,815\end{array}$ & $\begin{array}{l}49\left(9.8 \times 10^{-4}\right. \\
\text { of all } 49,823\end{array}$ & $\begin{array}{l}28\left(5.6 \times 10^{-4}\right. \\
\text { of all } 49,824\end{array}$ \\
\hline (False-positive rate) & $\begin{array}{l}\text { positions validated } \\
\text { in BeadChip) }\end{array}$ & $\begin{array}{l}\text { positions validated } \\
\text { in BeadChip) }\end{array}$ & $\begin{array}{l}\text { positions validated } \\
\text { in BeadChip) }\end{array}$ & $\begin{array}{l}\text { positions validated } \\
\text { in BeadChip) }\end{array}$ & $\begin{array}{l}\text { positions validated } \\
\text { in BeadChip) }\end{array}$ \\
\hline $\begin{array}{l}\text { Homozygous in }>10 \mathrm{Mb} \text { BeadChip } \mathrm{ROH} \\
\text { regions and heterozygous in NGS data }\end{array}$ & $5.9 \times 10^{-5}$ & $3.8 \times 10^{-5}$ & $2.2 \times 10^{-5}$ & $3.1 \times 10^{-4}$ & $2.6 \times 10^{-5}$ \\
\hline (Robust false-positive rate) & & & & & \\
\hline
\end{tabular}


Table 2 Summary of runs of homozygosity (ROHs) detected in whole genome sequencing data of ten horses

\begin{tabular}{|c|c|c|c|c|c|c|c|c|c|c|}
\hline & Horse 1 & Horse 2 & Horse 3 & Horse 4 & Horse 5 & Horse 6 & Horse 7 & Horse 8 & Horse 9 & Horse 10 \\
\hline & Dülmen & Sorraia & Sorraia & Hanoverian & Hanoverian & Hanoverian & Hanoverian & $\begin{array}{l}\text { Saxon-Thuringian } \\
\text { Heavy Warmblood }\end{array}$ & Arabian & $\begin{array}{l}\text { Thoroughbred } \\
\text { (SRR1055837) }\end{array}$ \\
\hline $\begin{array}{l}\text { Number of ROHs } \\
\text { (50) }\end{array}$ & 2804 & 4395 & 3955 & 2965 & 3214 & 3104 & 3167 & 3138 & 3581 & 4595 \\
\hline $\begin{array}{l}\text { Number of private } \\
\text { ROHs (50) }\end{array}$ & 722 & 1578 & 1349 & 538 & 752 & 662 & 709 & 739 & 934 & 1940 \\
\hline $\begin{array}{l}\text { Number of ROHs } \\
(500)\end{array}$ & 188 & 541 & 422 & 145 & 202 & 179 & 175 & 211 & 259 & 599 \\
\hline $\begin{array}{l}\text { Number of private } \\
\mathrm{ROHs}(500)\end{array}$ & 152 & 352 & 285 & 80 & 150 & 84 & 109 & 123 & 153 & 459 \\
\hline
\end{tabular}

The number of ROHs in windows of a minimum amount of 50 homozygous SNPs and 500 homozygous SNPs are shown. All ROHs were compared in-between horses and filtered for private $\mathrm{ROH}$ regions that could only be found in one horse

$50=$ A minimum amount of 50 homozygous SNPs

$500=\mathrm{A}$ minimum amount of 500 homozygous SNPs

\section{Private ROHs and functional annotation}

Functional annotation of genes located in private horse specific $\mathrm{ROH}$ regions, which could not be detected in one of the other horses under analysis, was performed in order to get an insight into biological processes affected by genes in horse specific homozygous segments. PANTHER gene list analysis for 50-SNP as well as 500-SNP windows revealed a high percentage of genes involved in cellular processes (GO:0009987), metabolic processes (GO:0008152) as well as biological regulations (GO:006
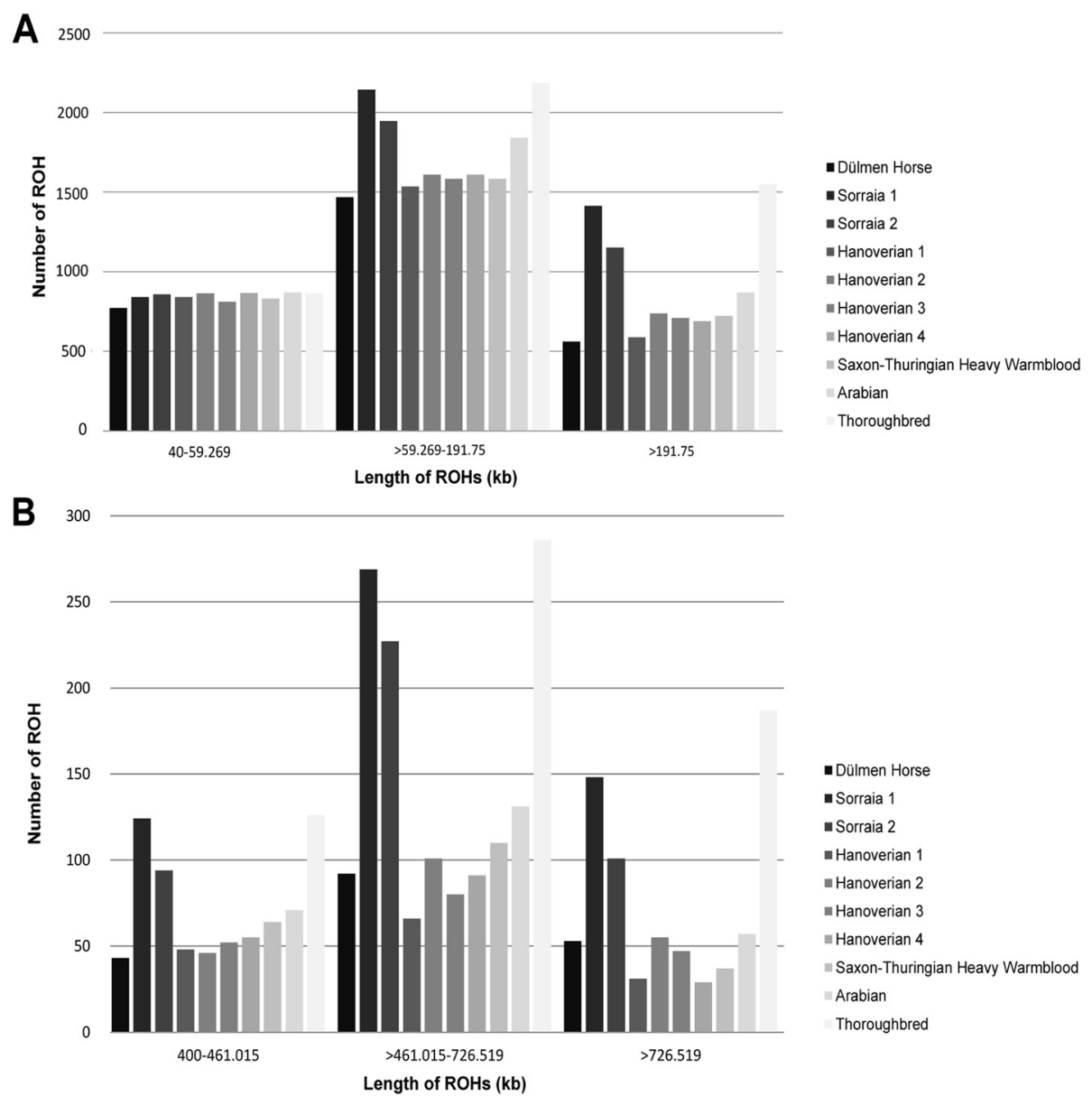

Fig. 1 Number and size of runs of homozygosity (ROH) detected in ten horses. The length of ROHs was categorized into small, medium and large $\mathrm{ROH}$ regions. The results of plink analysis with windows of minimum amount of 50 homozygous SNPs (a) and 500 homozygous SNPs (b) are shown 
Table 3 Functional annotations in private runs of homozygosity (ROH) of 50-SNP windows

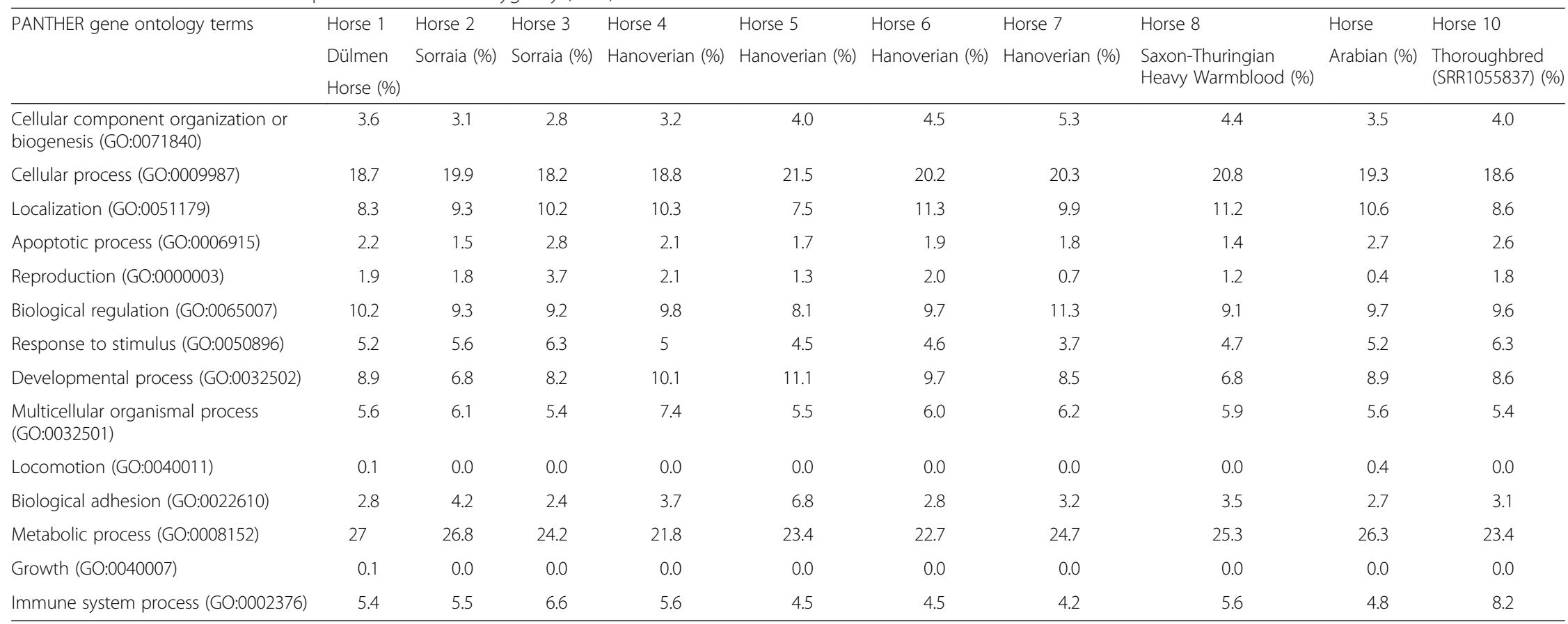

PANTHER gene list analysis (http://www.pantherdb.org/) was performed for genes in private ROH regions which could be exclusively found in one specific horse. The percent of gene hits against total number of process hits involved in specific biological processes are shown 
Table 4 Shared private runs of homozygosity $(\mathrm{ROH})$ in 50-SNP windows

\begin{tabular}{|c|c|c|c|c|c|c|}
\hline ECA & Position & $\begin{array}{l}\text { Number of SNPs in shared } \\
\text { parts of ROH regions }\end{array}$ & $\begin{array}{l}\text { Size of shared } \\
\mathrm{ROH}(\mathrm{bp})\end{array}$ & Gene ID & $\begin{array}{l}\text { Human } \\
\text { ortholog }\end{array}$ & Gene name/function \\
\hline 1 & 135530600-135573693 & 192 & 43094 & $\begin{array}{l}\text { ENSECAG000000010951, } \\
\text { ENSECAG00000001112, } \\
\text { ENSECAG00000004438, } \\
\text { ENSECAG00000001272 }\end{array}$ & $\begin{array}{l}\text { DYX1C1, } \\
\text { novel gene, } \\
\text { novel gene, } \\
\text { novel gene }\end{array}$ & $\begin{array}{l}\text { dyslexia susceptibility } 1 \\
\text { candidate } 1\end{array}$ \\
\hline 4 & $13434735-13434933$ & 17 & 199 & - & - & - \\
\hline 4 & $16813531-16813643$ & 4 & 113 & - & - & - \\
\hline 4 & $48740665-48745235$ & 7 & 4571 & - & - & - \\
\hline 6 & 70162066-70181092 & 35 & 19027 & ENSECAG00000006878 & CSAD & cysteine sulfinic acid decarboxylase \\
\hline 6 & $80540783-80586091$ & 227 & 45309 & ENSECAG00000024798 & TBC1D30 & TBC1 domain family, member 30 \\
\hline 6 & $81785611-81786700$ & 28 & 1090 & - & - & - \\
\hline 8 & 50498336-50582995 & 392 & 84660 & - & - & - \\
\hline 12 & 9146140-9204195 & 70 & 58056 & ENSECAG00000019892 & ALX4 & ALX homeobox 4 \\
\hline 14 & $30412967-30412967$ & 1 & 1 & - & - & - \\
\hline 14 & $85610289-85611904$ & 69 & 1616 & - & - & - \\
\hline 15 & 5973552-5973559 & 3 & 8 & - & - & - \\
\hline 15 & 79802636-79806388 & 119 & 3753 & - & - & - \\
\hline 16 & 23766626-23821105 & 311 & 54480 & ENSECAG00000002081 & novel gene & \\
\hline 22 & 4841367-4841408 & 3 & 42 & ENSECAG00000004364 & CFAP61 & $\begin{array}{l}\text { cilia and flagella associated } \\
\text { protein } 61\end{array}$ \\
\hline 22 & $16310734-16310750$ & 3 & 17 & - & - & - \\
\hline 28 & $39200676-39218496$ & 29 & 17821 & - & - & - \\
\hline 31 & 16634998-16711978 & 347 & 76981 & ENSECAG00000023857 & PPP1R14C & $\begin{array}{l}\text { protein phosphatase 1, regulatory } \\
\text { (inhibitor) subunit } 14 C\end{array}$ \\
\hline
\end{tabular}

The consensus $\mathrm{ROH}$ regions and genes in private $\mathrm{ROH}$ regions shared in four Hanoverian are shown. The number of SNPs and size of shared ROH indicate the overlap of homozygous variants

5007), localization (GO:0051179) and developmental pro cesses (GO:0032502) in all private $\mathrm{ROHs}$ of the analyzed ten horses (Table 3, Additional file 3). Further rates of gene hits affecting responses to stimulus (GO:0050896), cellular processes (GO:0071840; GO:0032501), immune system processes (GO:0002376), apoptotic processes (GO:0006915), biological adhesion (GO:0022610) and reproduction (GO:0000003) could also be observed in annotation results.

Analysis of shared private $\mathrm{ROHs}$ in specific breed horses revealed 18 ROHs common in all four Hanoverian but not in the other analyzed horses in 50-SNP windows and no shared ROHs in 500-SNP windows (Table 4). The $18 \mathrm{ROHs}$ contained four novel genes and six genes known as dyslexia susceptibility 1 candidate 1 (DYX1C1), protein phosphatase 1, regulatory (inhibitor) subunit 14C (PPP1R14C), cilia and flagella associated protein 61 (CFAP61/C20orf26), cysteine sulfinic acid decarboxylase (CSAD), TBC1 domain family, member 30 (TBC1D30) and $A L X$ homeobox 4 (ALX4), which were shown to be related by direct genetic interactions or coexpression (Fig. 2). A dense network of genetic interactions could also be found in-between genes located in private $\mathrm{ROHs}$ exclusively found in the non-breed horses
Dülmen Horse and Sorraia (Fig. 3 and 4). In total, 198 ROHs could be detected in 50-SNP windows covering 139 genes (Additional file 4). The largest ROHs for nonbreed horses of 324,707-163,116 base pairs were located in the region of the developmental and signaling genes secreted frizzled-related protein 2 (SFRP2), fraser extracellular matrix complex subunit 1 (FRAS1), interleukin-1 receptor-associated kinase 1 binding protein 1 (IRAK1BP1), pleckstrin homology domain interacting protein (PHIP), acyl-CoA synthetase short-chain family member 3 (ACSS3), protein tyrosine phosphatase, receptor type, $f$ polypeptide, interacting protein (liprin), alpha 2 (PPFIA2) and did also cover a gene-rich region which included spermatogenesis associated 25 (SPATA25), acyl-CoA thioesterase 8 (ACOT8) and troponin $C$ type 2 fast (TNNC2). $\mathrm{ROH}$ detection in 500-SNP windows revealed seven common $\mathrm{ROH}$ regions for non-breed horses. They were located on horse chromosomes 22 and 28 in or near by ROHs already found in 50SNP windows. The largest region showed a size of 576,454 base pairs. In contrast to non-breeds, the whole group of breed horses (Hanoverian, Arabian, Saxon-Thuringian Heavy Warmblood and Thoroughbred) revealed only three common ROHs in 50-SNP windows and no common ROHs in 500-SNP windows (Additional file 5). The largest 


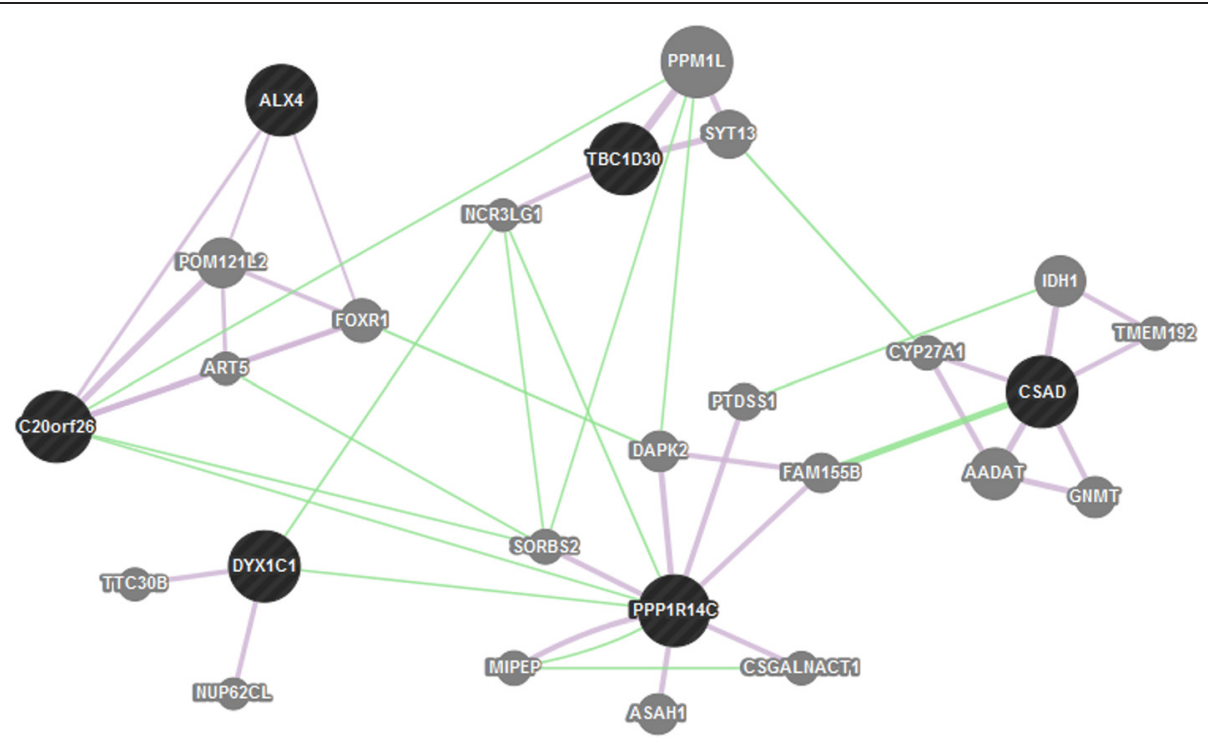

Fig. 2 GeneMANIA network of six genes in ROH regions shared by the Hanoverian. The genes of interest are represented as black circles, related genes as grey circles. Genetic interactions are displayed as green lines and co-expressions as violet lines. All six genes are interrelated with each other

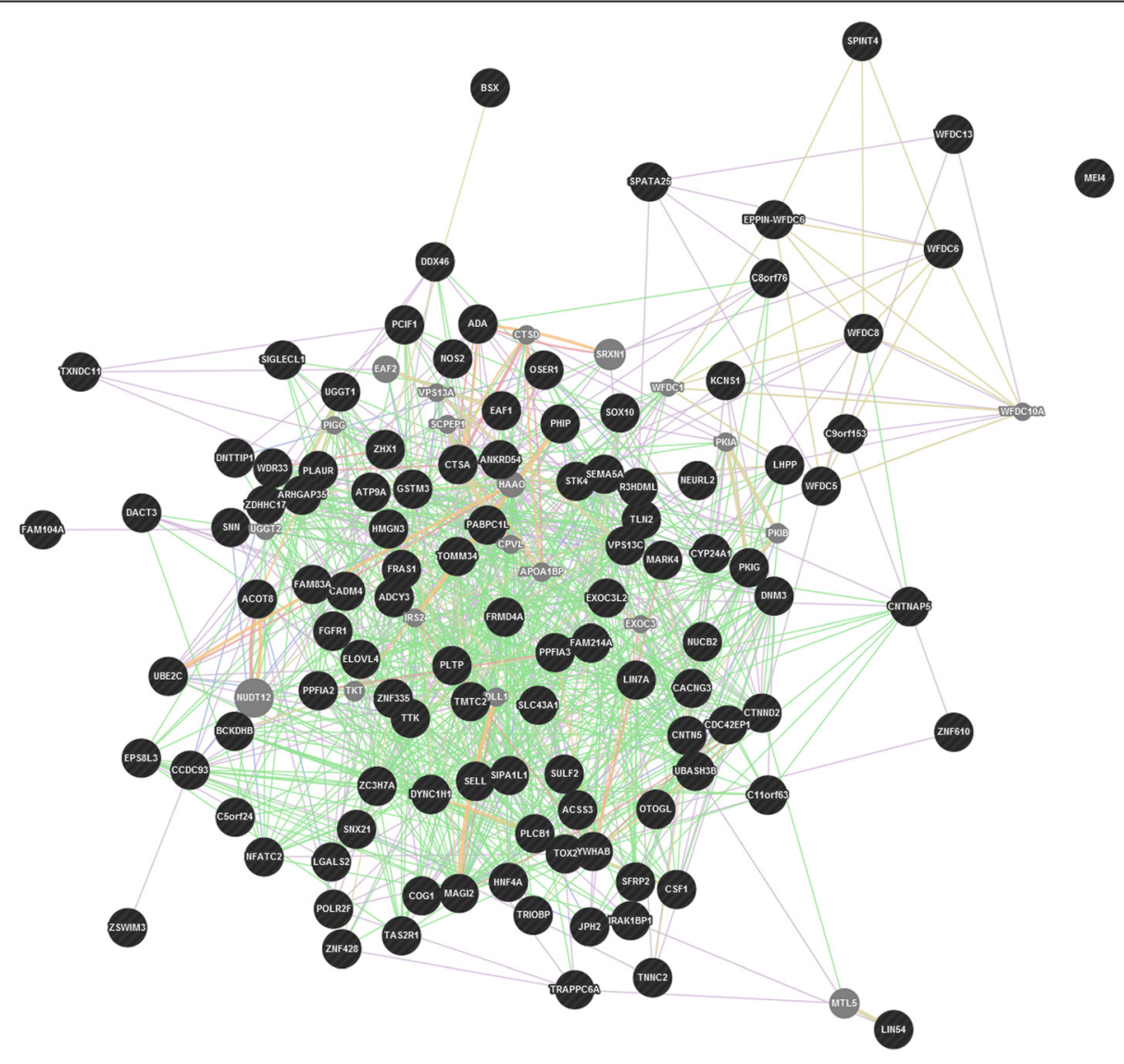

Fig. 3 GeneMANIA network of 139 genes in 50-SNP window ROH regions shared by non-breed horses. The genes of interest are represented as black circles, related genes as grey circles. Genetic interactions are displayed as light green lines, predicted related genes as orange lines, physical interactions as red lines, co-localization as blue lines, shared protein domains as dark green lines and co-expressions as violet lines 


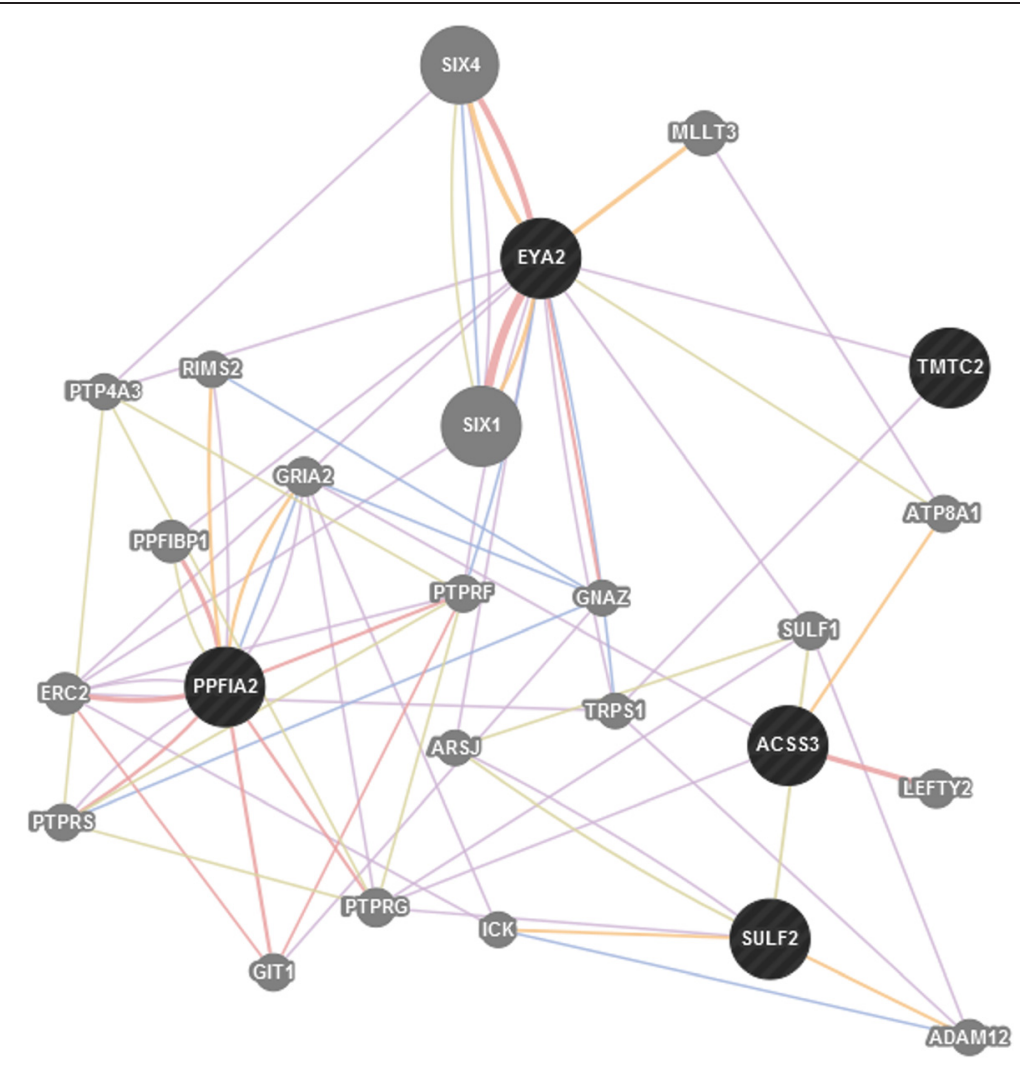

Fig. 4 GeneMANIA network of 7 genes in 500-SNP window ROH regions shared by non-breed horses. The genes of interest are represented as black circles, related genes as grey circles. Predicted related genes are displayed as orange lines, physical interactions as red lines, co-localization as blue lines, shared protein domains as dark green lines and co-expressions as violet lines

private $\mathrm{ROH}$ with 54,740 base pairs shared by all eight breed horses revealed a Tajima's D of -1.0 and could be shown to harbor the V-Yes-1 Yamaguchi Sarcoma Viral Oncogene Homolog 1 (YES1).

Evaluations of consensus ROHs for all ten horses revealed three $\mathrm{ROHs}$ which were all located on chromosome 28 at 14,656,676-14,778,472 $\mathrm{Mb}$ in the region of KIT ligand (KITLG, Table 5). No common ROHs could be found in 500-SNP windows in all ten horses. Tajima's $\mathrm{D}$ test statistics confirmed a deviation from neutrality in this region showing values below -1.2 in windows covering 14.65-14.78 Mb (Fig. 5, Additional file 6).

\section{Functional variations in $\mathrm{ROH}$ regions}

Private ROHs were further investigated for variants which might have a functional impact on horse group specific traits. In non-breed horses, 166 mutations with predicted high or moderate effects within $\mathrm{ROHs}$ of 50 SNP windows and 5 mutations within $\mathrm{ROHs}$ of $500-\mathrm{SNP}$ windows could be filtered out (Additional file 7 and 8). Three SNPs located on chromosome 10 at 19,334,666 (p.Val667Leu), 34,179,092 (p.Asp5Asn) and 34,221,357 $\mathrm{Mb}$ (p.Val208Ile) and one SNP on chromosome 28 at $8,441,975 \mathrm{Mb}$ (p.Met260Thr) were found homozygous for the mutated allele in the Dülmen Horse and the two Sorraia horses but heterozygous or homozygous wild type in all breed horses. The Val667Leu variant in exon 10 of Histidine Rich Calcium Binding Protein (HRC) was predicted to be deleterious (SIFT score 0.01) whereas the other three variants located in Elongation Of Very Long Chain Fatty Acids Protein 4 (ELOVL4), Phosphotyrosine Picked Threonine-Protein Kinase (TTK) and ACSS3 were

Table 5 Shared runs of homozygosity (ROH) in 50-SNP windows

\begin{tabular}{lllllll}
\hline ECA & Position & $\begin{array}{l}\text { Number of SNPs in shared } \\
\text { parts of ROH regions }\end{array}$ & $\begin{array}{l}\text { Size of shared } \\
\text { ROH }(\mathrm{bp})\end{array}$ & Gene ID & Human ortholog & Gene name/function \\
\hline 28 & $14656676-14778472$ & 310 & 121797 & ENSECAT00000000221 & KITLG & KIT ligand \\
28 & $14781594-14843608$ & 123 & 62015 & & \\
28 & $14844608-14951801$ & 175 & 107194 & & \\
\hline
\end{tabular}

The consensus $\mathrm{ROH}$ regions and genes in all ten horses are shown. The number of SNPs and size of shared ROH indicate the overlap of homozygous variants 


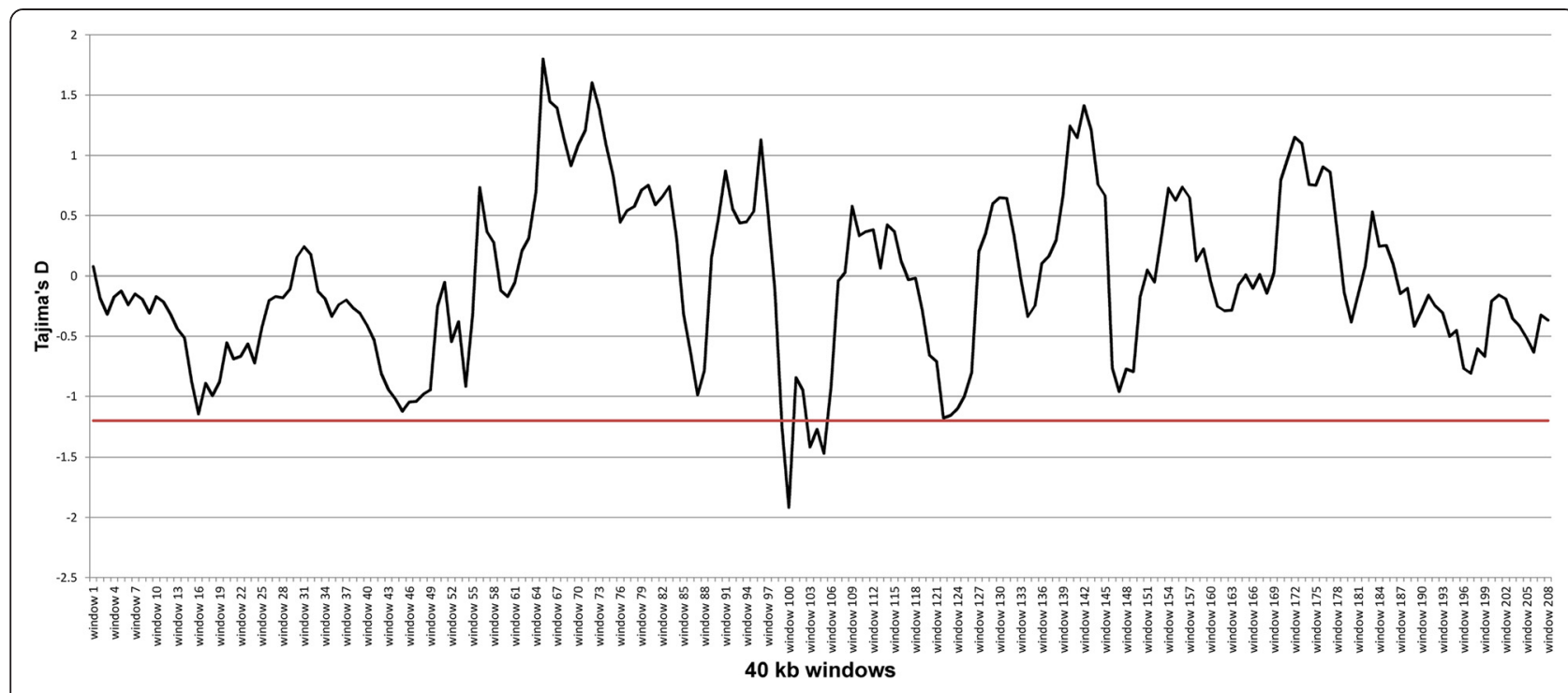

Fig. 5 Tajima's D estimate on equine chromosome 28 in the region of $13.68-15.75 \mathrm{Mb}$ for all ten horses. Decreased Tajima's D values below -1.2 can be observed in the consensus $\mathrm{ROH}$ extending over 14.65-14.78 Mb and harboring KITLG

proposed to be tolerated (SIFT score 0.32, 0.34, 0.12). In contrast to non-breeds, breed horses harbored no variants with high or moderate effects in private ROHs. Nevertheless, the four Hanoverians could be shown to harbor four SNPs in their private $\mathrm{ROH}$ regions in the genes $D Y X 1 C 1, C S A D$ and in the novel gene ENSECAG00000004438 (Additional file 9). These missense mutations showed no specific genotypes which could be exclusively found in the four Hanoverians. Furthermore, a closer examination of the consensus ROHs of all ten horses revealed a total of seven SNPs in the intronic region of KITLG but no variants with high or moderate effects.

\section{Discussion}

The detection of ROHs in ten horses of six different populations allowed us to estimate the genetic diversity in breeds or non-breeds and their signatures of potential selection. Smaller ROHs could be found in all horses to a very high number whereas ROHs of a larger size $>59 \mathrm{~kb}$ and also longer stretches of consecutive homozygous genotypes $>400 \mathrm{~kb}$ showed quite distinct distribution among different horse populations. Long homozygous stretches and consequently high inbreeding coefficients characterized the Sorraia and Thoroughbred, which were shown to be closed populations, as well as the Arabian derived from a relatively narrow genetic base [32-34]. Especially in the Thoroughbred the low genetic diversity was supposed to be a result of high selective pressures for specific traits of racing performance [12].

In contrast, the four Hanoverian sport horses in our study showed a low number of $\mathrm{ROHs}$ and relatively low values for $\mathrm{F}_{\mathrm{ROH}}$ indicative for inbreeding. Nevertheless, they shared 18 ROHs which harbored six genes potentially important for appearance and performance in sport horses. One of these genes, the homeodomain transcription factor coding gene $A L X 4$ was proposed to play an essential role in the skeletal mineralization and epidermal development in human and mice $[35,36]$. Neurologic activity could be shown to be affected by CSAD, regulating intracellular calcium levels in neurons by its influence on taurine biosynthesis, and DYX1C1 involved in neuronal migration [37-39]. The candidate gene $T B C 1 D 30$ has been characterized as a signal transducing peptide [40]. Comparative analyses of indicine and taurine cattle revealed signatures of selection and copy number variations in the region of TBC1D30 [41]. In KEPI (PPP1R14C)-knockout mice, a reduce response to repeated morphine injections suggested an important role of KEPI in the regulation of analgesic tolerance [42]. $K E P I$ was shown to be expressed in brain regions of drug reward, locomotor control and nociception [42, 43]. Furthermore, it was supposed to play an important role for the regulation of glycogen synthase by its inhibitive effect on protein phosphatase 1 (PP1) [44]. A significant impact on fertility could be observed in association with CFAP61 which was shown to affect cilia and flagella motility $[45,46]$. It can be assumed that these functional effects on neurologic control, signaling pathways, glycogen balance and reproduction might represent important targets of selection for the Hanoverian, which has become a specifically shaped breed into a modern sport horse type. In comparison to $\mathrm{ROH}$ analysis of all breed horses, the number of $\mathrm{ROHs}$ in the Hanoverian was relatively high probably as a result of breed specific similarities. However, despite significant differences in-between breeds, the 
whole group of breed horses revealed a region of potential selection harboring a fertility-related gene. YES1 could be shown to be an essential protein tyrosine kinase for selfdefensive mechanisms in spermatocytes [47]. During testicular heat stress a significantly upregulated expression of YES1 was supposed to antagonize apoptotic processes to maintain spermatogenic differentiation and male fertility. In addition to that, it was even more intriguing that $\mathrm{ROH}$ analyses in non-breed horses also suggested a high positive selection for reproduction in mainly naturally selected horses. One of the largest $\mathrm{ROHs}$ could be shown to harbor the fertility related gene SPATA25 which is known to be mainly expressed in testis in human. Studies of obstructive azoospermia revealed a significantly reduced expression level in affected patients in comparison to fertile persons [48]. Other candidate genes were proposed to be involved in embryonic development. Analyses of FRAS1 deficient mice revealed phenotypic defects affecting embryonic epithelial basement membranes and internal organs [49]. Furthermore a number of genes involved in energy metabolism (Acyl-coenzyme A synthetase 3, ACSS3; thioesterase 8, ACOT8) [50, 51] and muscle development (NEURL2) [52,53] could be found in large non-breed specific ROHs. The differentiation and survival of cardiomyocytes was supposed to be affected by SFRP2 [54]. It was shown that SFRP2 plays an important role in myocardial survival and is involved in ischemic injury repair of cardiomyocytes. The assumption of a potential non-breed specific effect on myocardial regulation for greater endurance in free range conditions was supported through the detection of a functional variant with a possibly deleterious impact on $H R C$. It was suggested that different expression levels of HRC can affect $\mathrm{CA}^{2+}$ homeostasis and contractile function of the heart $[55,56]$. In human and mice affected with heart failures, the HRC expression levels could be shown to be significantly decreased. In conclusion, we propose that non-breed horses underlie a selection mainly driven by nature which affects reproduction, embryonic development, energy metabolism and cardiac development traits. These results confirm the suggestion that metabolic processes and morphogenesis play an important role for survival and maintenance in non-breeds [57].

Despite the specific genetic features in non-breeds as well as breeds and the general differences in the number and length of $\mathrm{ROHs}$ in various horse breeds, a functional enrichment of genes affecting cellular, metabolic and developmental as well as immune system and reproduction processes could be shown in ROHs in all ten horses.

These results suggest that despite the low number of individuals in some breeds or non-breeds these ten horses presumably represent a general phenomenon in horse populations. We assume that regions of genes involved in fundamental processes essential for development and sustainment of individuals and populations underlie high selective pressures and accordingly limited variations. A main focus which could be found in all breeds, specific breeds (Hanoverian) and also in non-breeds was a potential selection for traits of reproduction. Essential genes for processes affecting fertility, embryonic development and birth varied among different horse populations but could be assumed to play a key role in artificial or natural selection as well. Reproduction performance has been shown to be of high economic importance in breeds and of vital importance for non-breeds to ensure survival in the wild $[5,58]$. Various studies in livestock came to the same conclusion and identified reproduction traits are essential targets of selection $[9,27,28]$.

This assumption is supported by our detection of three consensus ROHs in all ten horses which harbor only one annotated gene, the KITLG, also known as Mast Cell Growth Factor, Stem Cell Factor or steel factor [59, 60]. Scans for signatures of diversifying selection in pigs proposed the KITLG locus to be a breed-specific signature in the Berkshire [61]. Due to its complex functional capacity, KITLG has fundamental impact on various essential processes affecting melanogenesis, haematopoiesis and gametogenesis [59, 62, 63]. Mutations in KITLG and its receptor KIT were shown to affect multiple cell formation stages parallelly during embryonic development and in fully-grown mice $[63,64]$. The Steel Panda mutation at KITLG locus resulted in anemic black-eyed mice of white color with pigmented ears and scrotum and caused sterility in females. In human, a significant association for male infertility could be detected in KITLG affecting sperm count in patients [65]. In horses, the receptor of KITLG (KIT) was suggested to encode the dominant white (W) locus and to initiate severe disorders in haematopoietic system which might be responsible for the lethal consequences of homozygous W/W-genotype [66]. It was proposed that the dominant white phenotype is restricted in some breed registries due to the lethal effect of the homozygous dominant white mutation and also due to the risk of greater susceptibility to skin diseases. Therefore, we assume that the number of negative effects of KITLG mutations particularly affecting traits of reproduction and development have led to a strong positive selection of this region in horses that resulted in long ROHs.

The results of our study suggest that despite significant differences in-between breed and non-breed horses with regard to functional traits, all horse populations show strong signatures of selection in the region of genes affecting traits of reproduction.

\section{Methods}

\section{Ethics statement}

All animal work has been conducted according to the national and international guidelines for animal welfare. The 
EDTA-blood sampling was approved by the Institutional Animal Care and Use Committee (IACUC), the Lower Saxony state veterinary office at the Niedersächsisches Landesamt für Verbraucherschutz und Lebensmittelsi cherheit, Oldenburg, Germany (registration number 11A 160/7221.3-2.1-015/11, 8.84-02.05.20.12.066).

\section{Samples and sequencing}

Sequencing analysis was based on data from two Sorraia, one Dülmen Horse, one Arabian, one Saxon-Thuringian Heavy Warmblood, one Thoroughbred and four Hanoverian. Among these horses, six whole-genome sequences from two Hanoverian (SRX389480/SRX389477), one Arabian (SRX389472), one Sorraia (SRX389475), one Dülmen Horse (SRX384479) and one Thoroughbred (SRR1055837) were obtained from the Sequence Read Archive (NCBI). The remaining samples of a Sorraia mare, a Saxon-Thuringian Heavy Warmblood and two Hanoverian stallions were prepared for whole-genome sequencing. DNA was extracted from white blood cells derived from EDTA-blood sampling using Invisorb Spin Blood Mini kit according to the manufacturers' protocol (Stratec Biomedical, Birkenfeld, Germany). Paired-end libraries of the two Hanoverian were prepared using the Illumina DNA sample preparation kit (Illumina, San Diego, CA). DNA-samples were sheared on the Covaris (Covaris, Woburn, Massachusetts) and purified with Agencourt AMPure XP beads (Beckman Coulter, Krefeld, Germany). The remaining two samples (Sorraia and Saxon-Thuringian Heavy Warmblood) were prepared using the Illumina Nextera DNA Sample Prep Kit according to the manufacturers' protocol and purified with Agencourt AMPure XP beads as well. The whole genome of both Hanoverian was sequenced using an Illumina HiSeq2000 (Illumina) in paired-end mode $(2 \times 101 \mathrm{bp}$ reads), whereas the Sorraia and Saxon-Thuringian Heavy Warmblood were run on an Illumina MiSeq with v2 Reagent Kits ( $2 \times 250$ bp reads) four times paired-end on a single lane flowcell to reach an adequate coverage for whole genome sequencing.

Quality control of FASTQ-files was done using fastqc 0.11 .3 [67]. Reads were mapped to the reference genome EquCab2.70 using BWA 0.7.12 [68] and converted into binary format using SAMtools 1.2 [69]. PCR duplicated were marked using Picard tools (http://picard.sourceforge.net, version 1.130). Local realignment around INDELs, quality score recalibration and SNP calling was performed using GATK [70]. In order to get reliable data for variant detection we removed variants with a read depth $<2$ and $>1000$ and quality values $<20$ (qual). Variant annotation and effect prediction was done using SNPEff version 4.1 B (2015-0213) [71]. The VCF file was adapted to PLINK 1.07 format using SAS/Genetics 9.4 (Statistical Analysis System, Cary, $\mathrm{NC}$ ) and VCFtools 0.1.12b [72].
The data file for all ten horses re-sequenced is available at www.animalgenome.org (10horses.recode.vcf.gz). Raw data can be downloaded at the NCBI Sequence Read Archive (http://www.ncbi.nlm.nih.gov/sra), BioProject ID PRJNA291776 (Submission ID: SUB1048258).

\section{Runs of homozygosity}

ROHs were detected using a trimmed dataset of $11,325,777$ SNPs with a minimum read depth of 3, a maximum read depth of 60 and a minimum mean read depth of 12 for all ten samples. The X chromosome was omitted for this analysis. We defined $\mathrm{ROHs}$ as homozygous regions in sliding windows of 50 SNPs in a first run and 500 SNPs in a second approach using PLINK, version 1.07 (http://pngu.mgh.harvard.edu/purcell/plink/, [73]). Homozygous genotypes of $>40 \mathrm{~kb}$ as well as $>400 \mathrm{~kb}$ were defined as ROHs. The minimum distance of SNPs was estimated 0.8. This distance estimation was determined dividing the size of the genome covered with SNPs by the number of SNPs. No more than three SNPs with missing genotypes and three heterozygous SNPs were allowed in each window. The detected ROHs were categorized into small, medium and large ROHs and filtered for individual $\mathrm{ROH}$ regions for specific horses or breeds using SAS/Genetics, version 9.4. Private ROHs were determined by filtering out homozygous variants in $\mathrm{ROHs}$ in the horse of interest which could not be found in $\mathrm{ROHs}$ of other horses. Thus whole individual $\mathrm{ROHs}$ or individual parts of $\mathrm{ROHs}$ were detected as private ROHs for specific horses as well as for breeds or non-breeds. Consensus $\mathrm{ROH}$ regions were derived from intersections of homozygous variants in all ten horses. Furthermore inbreeding coefficients $\left(\mathrm{F}_{\mathrm{ROH}}\right)$ were estimated for each horse dividing the size of $\mathrm{ROHs}$ in bp by the length of the genome $(2,242,879,462 \mathrm{bp})$ covered with SNPs.

In addition to that, theta estimations and neutrality test statistics Tajima's D, Fu\&Li F's, Fu\&Li's D, Fay's H, Zeng's E were obtained using ANGSD version 0.902 [74]. Analyses were performed for all detected private ROHs in breed, non-breed and Hanoverian horses and for the consensus ROHs as well. Run parameters were adjusted to control for sequencing errors using a minimum quality value of $20(-\operatorname{minQ} 20)$ and filtering for a read depth of 3 to 60 (-geno_minDepth 3, -geno_maxDepth 60). Sliding windows of $40 \mathrm{~kb}$ as well as $400 \mathrm{~kb}$ were chosen for analysis.

\section{Sequence error detection by SNP50 BeadChip}

In addition to whole-genome sequencing, two horses (Hanoverian) of a previous study [57] and three horses (two Hanoverian and one Arabian) of the current study were genotyped on the Illumina SNP50 BeadChip. 
Sequence errors were estimated in comparison with BeadChip data identifying heterozygous SNPs in BeadChip data which were homozygous in NGS data as false-negative and homozygous SNPs in BeadChip data which were heterozygous in NGS data as false-positive. For a more robust estimation of average false-positive error rates, long $\mathrm{ROHs}>1 \mathrm{Mb}$ in sliding windows of 20 SNPs and a minimum distance of 50 were detected in BeadChip data using PLINK. No heterozygous SNPs and two missing called were admitted. These long $\mathrm{ROH}$ were assumed to hold error free homozygous genotypes and therefore ensure more precise error estimation in comparison with NGS-SNPs. The falsepositive error rates were taken into account in the $\mathrm{ROH}$ detection admitting three heterozygous SNPs in each sliding window.

\section{Functional annotation}

Gene lists of horse specific $\mathrm{ROH}$ regions were obtained using SAS/Genetics for filtering PLINK summary files and Galaxy intersection tool (https://usegalaxy.org/) [75-77] for gene allocation to genomic regions. The chromosomal positions of $\mathrm{ROHs}$ were aligned with the refseq gene table from UCSC (Ensembl genes) in order to obtain all genes located in ROHs. To improve functional analysis, we converted these gene lists to human orthologous genes using g:Profiler [78, 79]. PANTHER gene list analysis [80] was performed for functional classification of biological processes affected by genes in private $\mathrm{ROH}$ regions. In addition to these horse specific evaluations, further analyses for consensus ROHs in all ten horses and shared private $\mathrm{ROHs}$ in breed horses (Hanoverian, Arabian, Saxon-Thuringian Heavy Warmblood and Thoroughbred), non-breed horses (Dülmen Horse, Sorraia) and in the Hanoverian were performed. Gene names and its human orthologues were obtained using the Galaxy intersect function and g:Profiler as well. Genetic relations inbetween genes were obtained using GeneMANIA [81].

\section{Functional variant detection}

Functional variants with high or moderate effects were evaluated using SAS/Genetics for filtering SNPEff predictions categorized into high, moderate and low variant impacts. We determined the distribution of genotypes in relation to breed or non-breed groups and detected SIFT [82] prediction scores for functional effects using the Variant Effect Predictor [83].

\section{Additional files}

Additional file 1: Summary of mapping metrics, sequence coverage and number of detected variants in ten horses. (DOCX $174 \mathrm{~kb}$ )

Additional file 2: Inbreeding coefficients $\left(\mathrm{F}_{\mathrm{ROH}}\right)$ based on runs of homozygosity (ROH). $\mathrm{F}_{\mathrm{ROH}}$ was estimated dividing the total length of
ROHs by the length of the genome covered by SNPs $(2,242,879,462 \mathrm{bp})$. (DOCX $15 \mathrm{~kb}$ )

Additional file 3: Functional annotations in private runs of homozygosity (ROH) of 500-SNP windows. PANTHER gene list analysis (http://www.pantherdb.org/) was performed for genes in private $\mathrm{ROH}$ regions which could be exclusively found in one specific horse. The percent of gene hits against total number of process hits involved in specific biological processes are shown. (DOCX $18 \mathrm{~kb}$ )

Additional file 4: Shared runs of homozygosity (ROHs) in non-breed horses. The consensus private $\mathrm{ROH}$ regions and genes of the Dülmen Horse and two Sorraia in 50-SNP and 500-SNP windows are shown. The number of SNPs and size of shared $\mathrm{ROH}$ indicate the overlap of homozygous variants. (DOCX $78 \mathrm{~kb}$ )

Additional file 5: Shared runs of homozygosity (ROHs) in breed horses. The consensus private $\mathrm{ROH}$ regions and genes of Hanoverian, Arabian, Saxon-Thuringian Heavy Warmblood and Thoroughbred horses in 50-SNP windows are shown. The number of SNPs and size of shared $\mathrm{ROH}$ indicate the overlap of homozygous variants. (DOCX $14 \mathrm{~kb}$ )

Additional file 6: Theta estimations and neutrality test statistics for consensus and private ROHs. All private $\mathrm{ROH}$ s detected in the groups non-breed, breed and Hanoverian as well as in the region of KITLG were analyzed for Tajima's D, Fu\&Li F's, Fu\&Li's D, Fay's H, Zeng's E using the software ANGSD (http://popgen.dk/angsd). (XLSX 18 kb)

Additional file 7: Mutations with high or moderate effects in ROHs (50-SNP windows) of non-breed horses. The ROH position and size (EquCab2.70), the position of SNPs, their mutant allele, potential impact and type are shown. Impact estimations are derived from SNPEff predictions. (DOCX $65 \mathrm{~kb}$ )

Additional file 8: Mutations with high or moderate effects in ROHs (500-SNP windows) of non-breed horses. The $\mathrm{ROH}$ position and size (EquCab2.70), the position of SNPs, their mutant allele, potential impact and type are shown. Impact estimations are derived from SNPEff predictions. (DOCX $16 \mathrm{~kb}$ )

Additional file 9: Mutations with high or moderate effects in ROHs (50-SNP windows) of the four Hanoverians. The $\mathrm{ROH}$ position and size (EquCab2.70), the position of SNPs, their mutant allele, potential impact and type are shown. Impact estimations are derived from SNPEff predictions. (DOCX $15 \mathrm{~kb}$ )

\section{Abbreviations}

$\mathrm{ROH}$ : Runs of homozygosity; SNP: Single nucleotide polymorphism; NGS: Next generation sequencing; MSTN: Myostatin gene; PLAG1: Pleiomorphic adenoma gene 1; EDNRB: Endothelin receptor type B, DYX1C1, dyslexia susceptibility 1 candidate 1; PPP1R14C: Protein phosphatase 1, regulatory (inhibitor) subunit 14C; CFAP61/C20orf26: Cilia and flagella associated protein 61; CSAD: Cysteine sulfinic acid decarboxylase; TBC1D30: TBC1 domain family, member 30; ALX4: ALX homeobox 4; KITLG: KIT Ligand.

\section{Competing interests}

The authors declare that they have no competing interests.

\section{Authors' contributions}

$J M, M K$ and $O D$ designed the study. JM and OD carried out the experiments and data analysis, drafted and finalized the manuscript. RT, SB, LA, MG and IG performed HiSeq next generation sequencing, performed part of raw data analysis and helped to finalize the manuscript. All authors read and approved the final manuscript.

\section{Acknowledgements}

The authors thank the Hanoverian state stud Celle, the Hanoverian Breeding Association, the Arabian Horse Society (Verband der Züchter und Freunde des Arabischen Pferdes e.V.) and all horse owners for donation of data and samples. We also thank J. Wrede for his help in data analysis.

\section{Author details}

'Institute for Animal Breeding and Genetics, University of Veterinary Medicine Hannover, Bünteweg 17p, 30559 Hannover, Germany. ${ }^{2}$ Lower Saxony State Office for the Environment, Agriculture and Geology, Unit 74, Animal 
Breeding and Hygiene, Schlossallee 1, 01468 Moritzburg, Germany. ${ }^{3}$ Centro Nacional de Análisis Genómico, Parc Científic de Barcelona, Torre I Baldiri Reixac, 4, 08028 Barcelona, Spain

Received: 12 July 2015 Accepted: 3 October 2015 Published online: 09 October 2015

\section{References}

1. Petersen JL, Mickelson JR, Rendahl AK, Valberg SJ, Andersson LS, Axelsson J, et al. Genome-wide analysis reveals selection for important traits in domestic horse breeds. PLoS Genet. 2013;9(1):e1003211.

2. Makvandi-Nejad S, Hoffman GE, Allen JJ, Chu E, Gu E, Chandler AM, et al. Four Loci explain $83 \%$ of size variation in the horse. PLoS ONE. 2012;7(7):e39929.

3. Orlando L, Ginolhac A, Zhang G, Froese D, Albrechtsen A, Stiller M, et al. Recalibrating Equus evolution using the genome sequence of an early Middle Pleistocene horse. Nature. 2013;499(7456):74-8.

4. Brooks SA, Makvandi-Nejad S, Chu E, Allen JJ, Streeter C, Gu E, et al. Morphological variation in the horse: defining complex traits of body size and shape. Anim Genet. 2010:41 Suppl 2:159-65.

5. Beckmann S. Roentgenologische Untersuchung zur Osteochondrosis dissecans an Fessel-, Sprung-und Kniegelenken bei 85 Duelmener Wildpferden. Berlin: Freie Universitaet Berlin, Diss., 2011; 2011.

6. Pinheiro M, Kjöllerström HJ, Oom MM. Genetic diversity and demographic structure of the endangered Sorraia horse breed assessed through pedigree analysis. Livest Sci. 2013;152(1):1-10

7. Warmuth V, Manica A, Eriksson A, Barker G, Bower M. Autosomal genetic diversity in non-breed horses from eastern Eurasia provides insights into historical population movements. Anim Genet. 2013;44(1):53-61.

8. Ku CS, Naidoo N, Teo SM, Pawitan Y. Regions of homozygosity and their impact on complex diseases and traits. Hum Genet. 2011;129(1):1-15.

9. Bosse M, Megens HJ, Madsen O, Paudel Y, Frantz LA, Schook LB, et al. Regions of homozygosity in the porcine genome: consequence of demography and the recombination landscape. PLoS Genet. 2012;8(11):e1003100.

10. Purfield DC, Berry DP, McParland S, Bradley DG. Runs of homozygosity and population history in cattle. BMC Genet. 2012;13:70

11. Gibson J, Morton NE, Collins A. Extended tracts of homozygosity in outbred human populations. Hum Mol Genet. 2006;15(5):789-95.

12. Gu J, Orr N, Park SD, Katz LM, Sulimova G, MacHugh DE, et al. A genome scan for positive selection in thoroughbred horses. PLOS ONE. 2009;4(6):e5767.

13. Freedman AH, Gronau I, Schweizer RM, Ortega-Del Vecchyo D, Han E, Silva PM, et al. Genome sequencing highlights the dynamic early history of dogs. PLoS Genet. 2014;10(1):e1004016.

14. Kirin M, McQuillan R, Franklin CS, Campbell H, McKeigue PM, Wilson JF. Genomic runs of homozygosity record population history and consanguinity. PLoS ONE. 2010:5(11):e13996.

15. McQuillan R, Leutenegger AL, Abdel-Rahman R, Franklin CS, Pericic M, Barac-Lauc L, et al. Runs of homozygosity in European populations. Am J Hum Genet. 2008;83(3):359-72.

16. Nothnagel M, Lu TT, Kayser M, Krawczak M. Genomic and geographic distribution of SNP-defined runs of homozygosity in Europeans. Hum Mol Genet. 2010;19(15):2927-35.

17. Nalls M, Guerreiro R, Simon-Sanchez J, Bras J, Traynor B, Gibbs J, et al. Extended tracts of homozygosity identify novel candidate genes associated with late-onset Alzheimer's disease. Neurogenetics. 2009;10(3):183-90.

18. Alkuraya FS. The application of next-generation sequencing in the autozygosity mapping of human recessive diseases. Hum Genet. 2013:132(11):1197-211.

19. Lencz T, Lambert C, DeRosse P, Burdick KE, Morgan TV, Kane JM, et al. Runs of homozygosity reveal highly penetrant recessive loci in schizophrenia. Proc Natl Acad Sci U S A. 2007;104(50):19942-7.

20. Qanbari S, Pausch H, Jansen S, Somel M, Strom TM, Fries R, et al. Classic selective sweeps revealed by massive sequencing in cattle. PLoS Genet. 2014;10(2):e1004148.

21. Ai H, Huang L, Ren J. Genetic diversity, linkage disequilibrium and selection signatures in Chinese and Western pigs revealed by genome-wide SNP markers. PLoS ONE. 2013;8(2):e56001.

22. Boyko AR, Quignon P, Li L, Schoenebeck JJ, Degenhardt JD, Lohmueller KE, et al. A simple genetic architecture underlies morphological variation in dogs. PLoS Biol. 2010;8(8):e1000451.
23. Axelsson E, Ratnakumar A, Arendt M-L, Maqbool K, Webster MT, Perloski M, et al. The genomic signature of dog domestication reveals adaptation to a starch-rich diet. Nature. 2013;495(7441):360-4.

24. Pfahler S, Distl O. Effective Population Size, Extended Linkage Disequilibrium and Signatures of Selection in the Rare Dog Breed Lundehund. PLOS ONE. 2015;10(4):e0122680.

25. Ferenčaković M, Hamzić E, Gredler B, Solberg TR, Klemetsdal G, Curik I, et al. Estimates of autozygosity derived from runs of homozygosity: empirical evidence from selected cattle populations. J Anim Breed Genet. 2013;130(4):286-93.

26. Ferencakovic M, Hamzic E, Gredler B, Curik I, Sölkner J. Runs of homozygosity reveal genome-wide autozygosity in the Austrian Fleckvieh cattle. Agric Conspec Sci. 2011;76(4):325-9.

27. Qanbari S, Gianola D, Hayes B, Schenkel F, Miller S, Moore S, et al. Application of site and haplotype-frequency based approaches for detecting selection signatures in cattle. BMC Genomics. 2011;12(1):318.

28. Qanbari S, Pimentel E, Tetens J, Thaller G, Lichtner P, Sharifi A, et al. A genome-wide scan for signatures of recent selection in Holstein cattle. Anim Genet. 2010;41(4):377-89.

29. Kim E-S, Cole JB, Huson H, Wiggans GR, Van Tassell CP, Crooker BA, et al. Effect of artificial selection on runs of homozygosity in US Holstein cattle. PLoS ONE. 2013;8(11):e80813.

30. MacEachern S, Hayes B, McEwan J, Goddard M. An examination of positive selection and changing effective population size in Angus and Holstein cattle populations (Bos taurus) using a high density SNP genotyping platform and the contribution of ancient polymorphism to genomic diversity in Domestic cattle. BMC Genomics. 2009;10(1):181.

31. MacLeod IM, Larkin DM, Lewin HA, Hayes BJ, Goddard ME. Inferring demography from runs of homozygosity in whole-genome sequence, with correction for sequence errors. Mol Biol Evol. 2013;30(9):2209-23.

32. Aberle KS, Hamann H, Drögemüller C, Distl O. Genetic diversity in German draught horse breeds compared with a group of primitive, riding and wild horses by means of microsatellite DNA markers. Anim Genet. 2004;35(4):270-7.

33. Cunningham E, Dooley J, Splan R, Bradley D. Microsatellite diversity, pedigree relatedness and the contributions of founder lineages to thoroughbred horses. Anim Genet. 2001;32(6):360-4.

34. Khanshour A, Conant E, Juras R, Cothran EG. Microsatellite analysis of genetic diversity and population structure of Arabian horse populations. J Hered. 2013;104(3):386-98. doi:10.1093/jhered/est003.

35. Mavrogiannis LA, Antonopoulou I, Baxová A, Kutílek S, Kim CA, Sugayama SM, et al. Haploinsufficiency of the human homeobox gene ALX4 causes skull ossification defects. Nat Genet. 2001;27(1):17-8.

36. Kayserili H, Uz E, Niessen C, Vargel I, Alanay Y, Tuncbilek G, et al. ALX4 dysfunction disrupts craniofacial and epidermal development. Hum Mol Genet. 2009;18(22):4357-66.

37. Foos TM, Wu J-Y. The role of taurine in the central nervous system and the modulation of intracellular calcium homeostasis. Neurochem Res. 2002;27(1-2):21-6

38. Wang Y, Paramasivam M, Thomas A, Bai J, Kaminen-Ahola N, Kere J, et al, DYX1C1 functions in neuronal migration in developing neocortex. Neuroscience. 2006:143(2):515-22.

39. Taipale M, Kaminen N, Nopola-Hemmi J, Haltia T, Myllyluoma B, Lyytinen H, et al. A candidate gene for developmental dyslexia encodes a nuclear tetratricopeptide repeat domain protein dynamically regulated in brain. Proc Natl Acad Sci. 2003;100(20):11553-8.

40. Ishibashi K, Kanno E, Itoh T, Fukuda M. Identification and characterization of a novel Tre2/Bub2/Cdc16 (TBC) protein that possesses Rab3A GAP activity. Genes Cells. 2009:14(1):41-52

41. O'Brien AMP, Utsunomiya YT, Mészáros G, Bickhart DM, Liu GE, Van Tassell CP, et al. Assessing signatures of selection through variation in linkage disequilibrium between taurine and indicine cattle. Genet Sel Evol. 2014;46(1):19.

42. Drgonova J, Zimonjic DB, Hall FS, Uhl GR. Effect of KEPI (Ppp1r14c) deletion on morphine analgesia and tolerance in mice of different genetic backgrounds: when a knockout is near a relevant quantitative trait locus. Neuroscience. 2010;165(3):882-95.

43. Gong J-P, Liu Q-R, Zhang P-W, Wang Y, Uhl G. Mouse brain localization of the protein kinase $C$-enhanced phosphatase 1 inhibitor KEPI (kinase Cenhanced PP1 inhibitor). Neuroscience. 2005;132(3):713-27.

44. Newgard CB, Brady MJ, O'Doherty RM, Saltiel AR. Organizing glucose disposal: emerging roles of the glycogen targeting subunits of protein phosphatase-1. Diabetes. 2000;49(12):1967-77. 
45. Dymek EE, Smith EF. A conserved CaM-and radial spoke-associated complex mediates regulation of flagellar dynein activity. J Cell Biol. 2007;179(3):515-26.

46. Urbanska P, Song K, Joachimiak E, Krzemien-Ojak L, Koprowski P, Hennessey T, et al. The CSC proteins FAP61 and FAP251 build the basal substructures of radial spoke 3 in cilia. Mol Biol Cell. 2015;26(8):1463-75.

47. Liang Y, Dong Y, Zhao J, Li W. YES1 activation elicited by heat stress is anti-apoptotic in mouse pachytene spermatocytes. Biol Reprod. 2013;89(6):131. doi:10.1095/biolreprod.113.112235.

48. Zhou Y, Qin D, Tang A, Zhou D, Qin J, Yan B, et al. Developmental expression pattern of a novel gene, TSG23/Tsg23, suggests a role in spermatogenesis. Mol Hum Reprod. 2009;15(4):223-30.

49. Petrou P, Chiotaki R, Dalezios Y, Chalepakis G. Overlapping and divergent localization of Frem 1 and Fras1 and its functional implications during mouse embryonic development. Exp Cell Res. 2007;313(5):910-20.

50. Hunt MC, Rautanen A, Westin MA, Svensson LT, Alexson SE. Analysis of the mouse and human acyl-CoA thioesterase (ACOT) gene clusters shows that convergent, functional evolution results in a reduced number of human peroxisomal ACOTs. FASEB J. 2006;20(11):1855-64.

51. Watkins PA, Maiguel D, Jia Z, Pevsner J. Evidence for 26 distinct acylcoenzyme A synthetase genes in the human genome. J Lipid Res. 2007:48(12):2736-50.

52. Nastasi T, Bongiovanni A, Campos Y, Mann L, Toy JN, Bostrom J, et al. Ozz-E3, a muscle-specific ubiquitin ligase, regulates $\beta$-catenin degradation during myogenesis. Dev Cell. 2004;6(2):269-82.

53. Gahlmann R, Kedes L. Cloning, structural analysis, and expression of the human fast twitch skeletal muscle troponin C gene. J Biol Chem. 1990;265(21):12520-8.

54. Mirotsou M, Zhang Z, Deb A, Zhang L, Gnecchi M, Noiseux N, et al. Secreted frizzled related protein 2 (Sfrp2) is the key Akt-mesenchymal stem cell-released paracrine factor mediating myocardial survival and repair. Proc Natl Acad Sc. 2007;104(5):1643-8.

55. Fan G-C, Gregory KN, Zhao W, Park WJ, Kranias EG. Regulation of myocardial function by histidine-rich, calcium-binding protein. Am J Physiol Heart Circ Physiol. 2004;287(4):H1705-11.

56. Gregory KN, Ginsburg KS, Bodi I, Hahn H, Marreez YM, Song Q, et al. Histidinerich $\mathrm{Ca}$ binding protein: a regulator of sarcoplasmic reticulum calcium sequestration and cardiac function. J Mol Cell Cardiol. 2006;40(5):653-65.

57. Metzger J, Tonda R, Beltran S, Agueda L, Gut M, Distl O. Next generation sequencing gives an insight into the characteristics of highly selected breeds versus non-breed horses in the course of domestication. BMC Genomics. 2014;15(1):562.

58. Hamann H, Jude R, Sieme H, Mertens U, Töpfer-Petersen E, Distl O, et al. A polymorphism within the equine CRISP3 gene is associated with stallion fertility in Hanoverian warmblood horses. Anim Genet. 2007;38(3):259-64

59. Matsui $Y$, Zsebo KM, Hogan BL. Embryonic expression of a haematopoietic growth factor encoded by the SI locus and the ligand for c-kit. Nature. 1990;347(6294):667-9.

60. Seitz JJ, Schmutz SM, Thue TD, Buchanan FC. A missense mutation in the bovine MGF gene is associated with the roan phenotype in Belgian Blue and Shorthorn cattle. Mamm Genome. 1999;10(7):710-2.

61. Wilkinson S, Lu ZH, Megens H-J, Archibald AL, Haley C, Jackson IJ, et al. Signatures of diversifying selection in European pig breeds. 2013.

62. Wehrle-Haller B. The role of Kit-ligand in melanocyte development and epidermal homeostasis. Pigment Cell Res. 2003;16(3):287-96.

63. Beechey C, Loutit J, Searle A. Panda, a new steel allele. Mouse News Lett 1986;74(92):52.

64. Huang EJ, Manova K, Packer Al, Sanchez S, Bachvarova RF, Besmer P. The murine steel panda mutation affects kit ligand expression and growth of early ovarian follicles. Dev Biol. 1993;157(1):100-9.

65. Galan J, De Felici M, Buch B, Rivero M, Segura A, Royo J, et al. Association of genetic markers within the KIT and KITLG genes with human male infertility. Hum Reprod. 2006;21(12):3185-92.

66. Mau C, Poncet PA, Bucher B, Stranzinger G, Rieder S. Genetic mapping of dominant white $(W)$, a homozygous lethal condition in the horse (Equus caballus). J Anim Breed Genet. 2004;121:374-83.

67. Andrews S. FastQC: A quality control tool for high throughput sequence data. Reference Source. 2010.

68. Li H, Durbin R. Fast and accurate long-read alignment with BurrowsWheeler transform. Bioinformatics. 2010;26(5):589-95.

69. Li H, Handsaker B, Wysoker A, Fennell T, Ruan J, Homer N, et al. The sequence alignment/map format and SAMtools. Bioinformatics. 2009;25(16):2078-9.
70. McKenna A, Hanna M, Banks E, Sivachenko A, Cibulskis K, Kernytsky A, et al. The Genome Analysis Toolkit: a MapReduce framework for analyzing nextgeneration DNA sequencing data. Genome Res. 2010;20(9):1297-303.

71. Cingolani P, Platts A, le Wang $L$, Coon M, Nguyen T, Wang L, et al. A program for annotating and predicting the effects of single nucleotide polymorphisms, SnpEff: SNPs in the genome of Drosophila melanogaster strain w1118; iso-2; iso-3. Fly (Austin). 2012;6(2):80-92.

72. Danecek P, Auton A, Abecasis G, Albers CA, Banks E, DePristo MA, et al. The variant call format and VCFtools. Bioinformatics. 2011;27(15):2156-8.

73. Purcell S, Neale B, Todd-Brown K, Thomas L, Ferreira MA, Bender D, et al. PLINK: a tool set for whole-genome association and population-based linkage analyses. Am J Hum Genet. 2007;81(3):559-75.

74. Korneliussen TS, Moltke I, Albrechtsen A, Nielsen R. Calculation of Tajima's D and other neutrality test statistics from low depth next-generation sequencing data. BMC Bioinformatics. 2013;14(1):289.

75. Goecks J, Nekrutenko A, Taylor J. Galaxy: a comprehensive approach for supporting accessible, reproducible, and transparent computational research in the life sciences. Genome Biol. 2010;11(8):R86.

76. Blankenberg D, Kuster GV, Coraor N, Ananda G, Lazarus R, Mangan M, et al. Galaxy: a web-based genome analysis tool for experimentalists. Curr Protoc Mol Biol. 2010; Chapter 19:Unit 19.10:1-21.

77. Giardine B, Riemer C, Hardison RC, Burhans R, Elnitski L, Shah P, et al. Galaxy: a platform for interactive large-scale genome analysis. Genome Res. 2005;15(10):1451-5.

78. Reimand J, Kull M, Peterson H, Hansen J, Vilo J. g: Profiler-a web-based toolset for functional profiling of gene lists from large-scale experiments. Nucleic Acids Res. 2007;35 suppl 2:W193-200.

79. Reimand J, Arak T, Vilo J. g:Profiler-a web server for functional interpretation of gene lists (2011 update). Nucleic Acids Res. 2011;39(Web Server issue):W307-315.

80. Mi H, Muruganujan A, Thomas PD. PANTHER in 2013: modeling the evolution of gene function, and other gene attributes, in the context of phylogenetic trees. Nucleic Acids Res. 2013;41(D1):D377-386.

81. Warde-Farley D, Donaldson SL, Comes O, Zuberi K, Badrawi R, Chao P, et al. The GeneMANIA prediction server: biological network integration for gene prioritization and predicting gene function. Nucleic Acids Res. 2010;38 suppl 2:W214-20.

82. Kumar P, Henikoff S, Ng PC. Predicting the effects of coding non-synonymous variants on protein function using the SIFT algorithm. Nat Protoc. 2009;4(7):1073-81.

83. McLaren W, Pritchard B, Rios D, Chen Y, Flicek P, Cunningham F. Deriving the consequences of genomic variants with the Ensembl API and SNP Effect Predictor. Bioinformatics. 2010;26(16):2069-70.

\section{Submit your next manuscript to BioMed Central and take full advantage of:}

- Convenient online submission

- Thorough peer review

- No space constraints or color figure charges

- Immediate publication on acceptance

- Inclusion in PubMed, CAS, Scopus and Google Scholar

- Research which is freely available for redistribution

Submit your manuscript at www.biomedcentral.com/submit

C Biomed Central 